\title{
Crystallization kinetics and thermal degradation behavior of low- density polyethylene blended with poly(bispropoxyphosphazene)
}

\author{
Wen-Yen Chiu ${ }^{\text {a,* }}$, Fa-Tai Wang ${ }^{\text {a }}$, Leo-Wang Chen ${ }^{\text {a }}$, Trong-Ming Don ${ }^{\text {a, }}{ }_{\text {, }}$ \\ Ching-Yuan Lee ${ }^{\mathrm{b}}$ \\ ${ }^{a}$ Department of Chemical Engineering, National Taiwan University, Taipei, Taiwan, ROC \\ ${ }^{\mathrm{b}}$ Chemical System Research Division, Chung Shan Institute of Science and Technology, Taoyuan, Taiwan, ROC
}

Received 2 April 1999; accepted 9 June 1999

\begin{abstract}
Low-density polyethylene (LDPE) was melt blended in a Brabender with different amounts of poly(bispropoxyphosphazene) flame retardant, MFR. The crystallization kinetics and thermal degradation behavior of the blends were investigated. It was found that MFR was incompatible with LDPE, where MFR particles dispersed in LDPE matrix with very weak interfacial bonding. In the blends, polyethylene crystals were still in an orthorhombic form and spherulitic structure was observed. Under isothermal crystallization, the crystallization rate and crystallinity were both increased with the addition of MFR up to 20 phr, probably due to the decrease of viscosity and the increase in the number of nucleation sites. The Avrami parameter $n$ was in the range of 2.2 to 2.7 for the blends. In thermal degradation behavior, the addition of MFR increased the maximum-rate degradation temperature $\left(T_{\max }\right)$, char yield at $650^{\circ} \mathrm{C}$ and the limiting oxygen index (LOI) of LDPE, indicating that MFR additive was beneficial in flame retardancy. Yet, it deteriorated the tensile mechanical properties of LDPE. (C) 2000 Elsevier Science Ltd. All rights reserved.
\end{abstract}

Keywords: Low-density polyethylene; Poly(bispropoxyphosphazene); Blends; Flame retardant; Crystallization kinetics; Thermal degradation behavior

\section{Introduction}

The thermal degradation behavior of polyethylene (PE) has been studied for many years. As early as in 1949, Straus et al. [1] believed that the degradation of PE was due to the random chain scission, since the pyrolysis products were composed of mainly hydrocarbons from C-1 to C-50. Tsuchiya and Sumi [2] proposed a free-radical chain scission mechanism to explain the thermal degradation behavior of a high densitypolyethylene (HDPE). Grassie [3] also reported that PE degraded randomly along the main chain. PE was very thermally stable before $290^{\circ} \mathrm{C}$; after that, it started to degrade yet with very small amount of volatile until $360^{\circ} \mathrm{C}$. As the temperature was raised above $360^{\circ} \mathrm{C}$, the

\footnotetext{
* Corresponding author. Fax: + 886-2-2362-3040.

E-mail address: ycchiu@ccms.ntu.edu.tw (W-Y. Chiu).

${ }^{1}$ Present address: Department of Chemical Engineering, Mingchi Institute of Technology, Taipei Shein, Taiwan, ROC.
}

degradation rate increased quickly and a quantity of volatile, seldom monomer-type compounds, was produced. Seeger and Barrall [4] studied the thermal degradation behavior of HDPE, LDPE and ethylenepropylene copolymer. They pointed out that the scission rate of $\mathrm{C}-\mathrm{C}$ bond at $\alpha$ and $\beta$ position next to the tertiary carbon was twice as fast as the rest of linear chain, i.e. the more the branched chains, the more the iso-alkane compounds produced during degradation.

Flame-retardants are generally added into the organic polymers, since most of them do not have sufficient flame retardancy and burn easily. Among them, phosphorous compounds are increasingly popular over their halogen counterparts, since they generally give off nontoxic and non-corrosive volatile combustion products. Therefore, in this study, a poly(bispropoxyphosphazene) flame retardant, MFR, with high phosphorus and nitrogen content was melt blended with a LDPE. The effect of MFR additive on the crystallization kinetics of LDPE was first investigated. Then, the thermal degradation behavior of the blends with different amounts of MFR was studied. Finally, the flammability 
of these blends was evaluated by measuring their limiting oxygen index (LOI) values and smoke densities.

\section{Experimental}

\subsection{Materials}

Low-density polyethylene (LDPE) having a density of $0.914 \mathrm{~g} / \mathrm{cm}^{3}$ was supplied by USI Far East Corporation. It has a melting index of $46 \mathrm{~g} / 10 \mathrm{~min}$. Poly(bispropoxyphosphazene), MFR, was kindly supplied by Chung-Shan Institute of Science and Technology. It has a viscosity of $35000 \mathrm{cps}$ at $25^{\circ} \mathrm{C}$ and chlorine content less than $1 \%$. The chemical structure of this MFR is indicated below.<smiles>C=NP(C)(C)(OCC)OCC</smiles>

Prior to blending, LDPE pellets were dried in an oven at $105^{\circ} \mathrm{C}$ for at least $24 \mathrm{~h}$. Various parts of MFR was blended with 100 parts of LDPE in a Brabender at $135^{\circ} \mathrm{C}$ for $30 \mathrm{~min}$. The rotation speed was set at $30 \mathrm{rpm}$. After blending, the mixture was removed from the mixer and placed in a mold sitting on a hot-press machine. The dimension of the mold was $15 \mathrm{~cm} \times 15$ $\mathrm{cm} \times 3 \mathrm{~mm}$. The composition and the code of the blends are listed in Table 1

\subsection{Structure analysis}

A Fourier transform infrared (FTIR) spectrophotometer from JASCO FTIR 300-E was used to analyze the chemical and/or physical interactions between LDPE and MFR in the blends. The crystal structure and its morphology were studied using an X-ray diffractometer from Phillips PW-1710 and an optical microscope equipped with a polarizer from Zeiss Inc.

Table 1

The composition of various blends and their phosporus content (wt \%)

\begin{tabular}{lcll}
\hline Sample & $\begin{array}{l}\text { Composition } \\
\text { (phr MFR) }\end{array}$ & $\begin{array}{l}\text { Phosphorus } \\
\text { content }(\%) \\
\text { (theoretical value) }\end{array}$ & $\begin{array}{l}\text { Phosphorus } \\
\text { content }(\%) \\
\left.\text { (experimental value }{ }^{\mathrm{b}}\right)\end{array}$ \\
\hline MFR & - & 21 & 21 \\
LDPE0F & 0 & 0 & $<0.2$ \\
LDPE5F & 5 & 1.05 & 0.93 \\
LDPE10F & 10 & 2.01 & 1.92 \\
LDPE15F & 15 & 2.21 & 2.67 \\
LDPE20F & 20 & 3.68 & 3.45 \\
LDPE25F & 25 & 4.42 & 4.03 \\
\hline
\end{tabular}

a Based on 100 phr of LDPE.

b The phosphorus content was determined by colorimetry.

\subsection{Crystallization kinetics}

A differential scanning calorimeter (DSC) from TA Company, TA 2000, was used to study the crystallization behavior of MFR/LDPE blends. In the isothermal crystallization process, samples were first heated to $135^{\circ} \mathrm{C}$ and hold for $10 \mathrm{~min}$, followed by cooling down to a specific temperature at a rate of $40^{\circ} \mathrm{C} /$ min. The crystallization exothermic heat was then observed with time. The relative crystallinity, $X_{r}(t)$, was calculated from the ratio of integrated area at some specific time to the total area under the exothermic curve. In the dynamic mode, samples were first heated to $135^{\circ} \mathrm{C}$ and hold for $5 \mathrm{~min}$ to erase the thermal history, and then either were quenched to $-140^{\circ} \mathrm{C}$ or cooled down slowly at $5^{\circ} \mathrm{C} / \mathrm{min}$ to room temperature. The samples were then heated again at $5^{\circ} \mathrm{C} / \mathrm{min}$ to $140^{\circ} \mathrm{C}$. Crystallization temperature $\left(T_{c}\right)$ and melting temperature $\left(T_{m}\right)$ were calculated from the various thermograms.

\subsection{Thermal degradation behavior}

The thermal degradation behavior of MFR/LDPE blends was investigated using a Perkin-Elmer TGA 7 thermal gravimetric analysis at various heating rates under nitrogen and air atmosphere, respectively.

\subsection{Mechanical properties}

Tensile properties: ultimate tensile strength, initial modulus and elongation at break, were measured using Universal Tensile Testing Instrument, RTM-1, from Yashima Works Company, according to ASTM D638 with specimen type $\mathrm{I} \nabla$. The tensile speed was $20 \mathrm{~mm} / \mathrm{min}$.

\subsection{Morphology observation}

A scanning electron microscope, model JEOL TSM6300, was used to observe the morphology of the blends. Samples were first quenched in liquid nitrogen and immediately were fractured. The fractured surfaces were coated with gold using a sputter coater.

\subsection{Flammability}

A limiting oxygen index (LOI) tester from Polymer Lab. Ltd. was used to measure the LOI values of various blends following ASTM D2863 method. The specimen dimension was $140 \times 52 \times 3 \mathrm{~mm}$. The smoke density was determined by measuring the specific optical density $\left(D_{s}\right)$ of various blends following ASTM E-662 method. The size of specimen was $75 \times 75 \times 3 \mathrm{~mm}$ and the heat flux was $25 \mathrm{~kW} / \mathrm{m}^{2}$. The maximum smoke density $\left(D_{m}\right)$, the rate of increase of smoke density $(R)$ and the time required to reach $D_{s}=16\left(t_{\mathrm{D} 16}\right)$ were calculated. The rate $R$ was calculated from the equation indicated below: 


$$
\begin{array}{r}
R=\frac{1}{4}\left[\frac{0.9 D_{m}-0.7 D_{m}}{t_{0.9}-t_{0.7}}+\frac{0.7 D_{m}-0.5 D_{m}}{t_{0.7}-t_{0.5}}\right. \\
\left.+\frac{0.5 D_{m}-0.3 D_{m}}{t_{0.5}-t_{0.3}}+\frac{0.3 D_{m}-0.1 D_{m}}{t_{0.3}-t_{0.1}}\right]
\end{array}
$$

where $t_{0.9}, t_{0.7}, \ldots, t_{0.1}$ were the time needed when $D_{s}$ reached $0.9 \quad D_{m}, 0.7 \quad D_{m}, \ldots, 0.1 \quad D_{m}$, respectively. Another parameter, index of the reduction in visibility or smoke obscuration index (SOI), was also calculated by the following equation:

$\mathrm{SOI}=\frac{D_{m} \times R}{100 \times t_{\mathrm{D}_{16}}}$

\section{Results and discussion}

\subsection{Structure analysis}

Fig. 1 shows FTIR spectra of MFR, a neat LDPE (LDPE0F) and a blend containing $20 \mathrm{phr}$ MFR (LDPE20F). It can be seen that the spectrum of LDPE20F is only the addition of the two spectra from the corresponding MFR and LDPE components. This indicates that there is no chemical bonding between the MFR and LDPE. There is even no shift in the characteristic absorption peaks indicating that LDPE did not have strong interaction with MFR. Several characteristic absorption peaks are shown in Table 2.
The X-ray diffraction patterns of various blends are shown in Fig. 2. There is no shift or apparently decrease in intensity of the peaks corresponding to the (110) and (200) reflections from the orthorhombic polyethylene crystals. Therefore, the presence of MFR and the blending method had no effect on the polyethylene crystalline structure. Fig. 3 shows the optical micrographs of various blends under isothermal crystallization at $94^{\circ} \mathrm{C}$ for $3 \mathrm{~h}$. Spherulitic structure was observed for all the blends. Yet with the more addition of MFR, the size of spherulites decreased and the distribution of spherulites was less uniform. This is probably because the addition of MFR increased the heterogeneous nucleation.

\subsection{Morphology observation}

Fig. 4 shows the SEM micrographs of the fracture surface of various blends. From the pictures, it can be seen that MFR and LDPE were not compatible, where MFR particles dispersed in LDPE matrix. During the fracture, some of MFR particles were ripped off, leaving the voids on the surface. This indicates that MFR did not have strong bonding with LDPE. As the amount of MFR additive increased, the size of particles or voids increased as well.

\subsection{Crystallization kinetics}

Various MFR/LDPE blends were heated to $135^{\circ} \mathrm{C}$ to the melt state, and then cooled down at $40^{\circ} \mathrm{C} / \mathrm{min}$ to the pre-set temperature. The crystallization exothermic heat

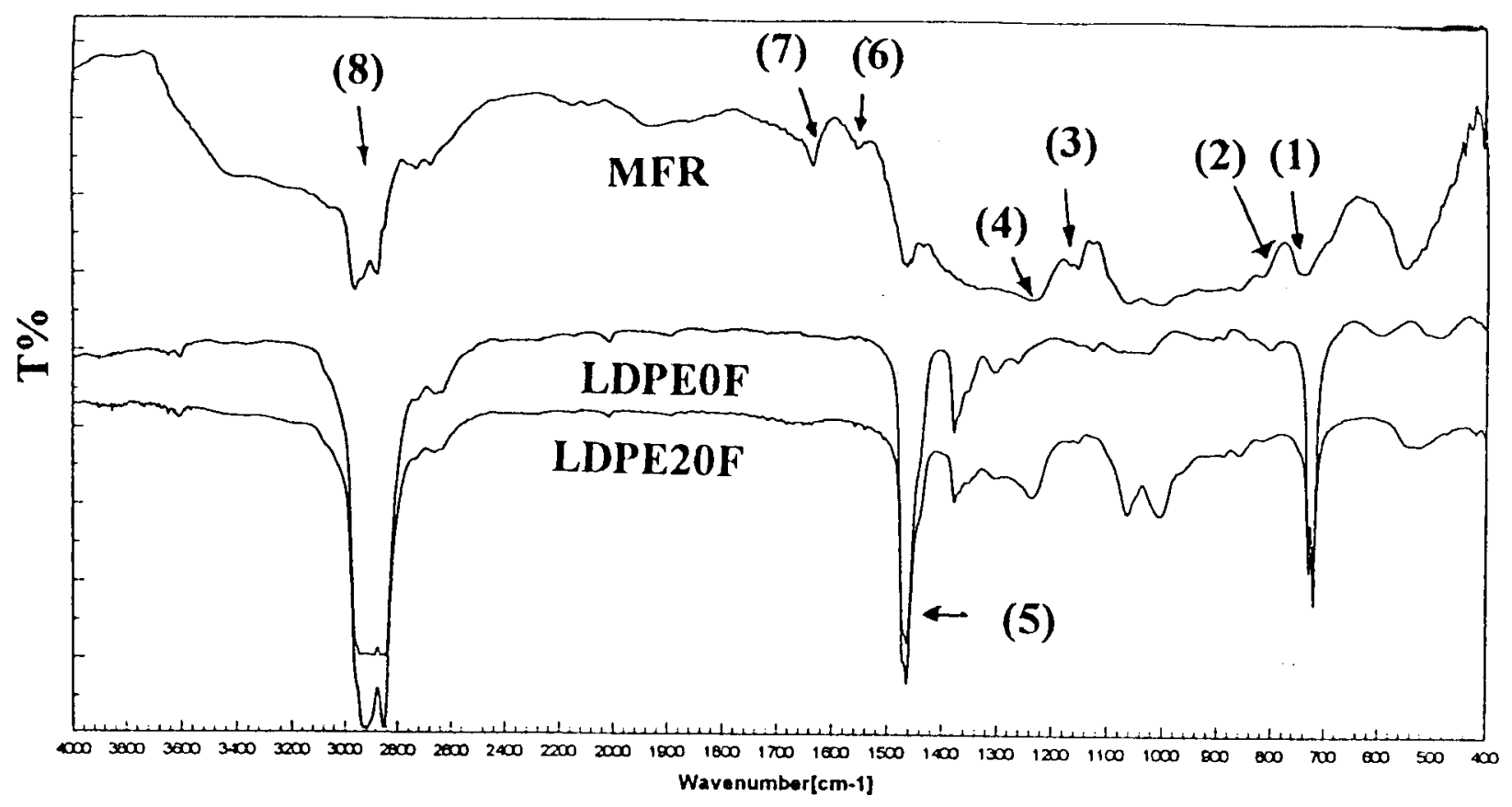

Fig. 1. FTIR spectra of MFR, a neat LDPE and a LDPE20F blend. 
then was observed with time, and the relative crystallinity $\left(X_{r}\right)$ was calculated from the area under the curve. Table 3 shows the values of several parameters calculated from these crystallization exothermic peaks of various samples at some specific crystallization temperatures $\left(T_{c}\right)$. In the Table, the Avrami parameters, $n$ and $k$, were determine by plotting $\ln \left(-\ln \left(1-X_{r}\right)\right)$ versus $\ln (t)$ transformed from the Avrami equation, $1-X_{r}=\exp \left(-k t^{n}\right)$. A typical plot was shown in Fig. 5 for the blend LDPE20F. The $n$ values were in the range of 2.7 to 2.2 for all blends and decreased with the addition of MFR. Table 3 also shows $t_{\max }$ and $t_{1 / 2}$, which were the times to reach the maximum of the exothermic peak and to reach $X_{r}=50 \%$ (half-life time), respectively. Both of

Table 2

Characteristic FTIR absorption peaks of MFR and LDPE

\begin{tabular}{llll}
\hline $\begin{array}{l}\text { Functional } \\
\text { group }\end{array}$ & $\begin{array}{l}\text { Wavenumber } \\
\left(\mathrm{cm}^{-1}\right)\end{array}$ & Type $^{\mathrm{a}}$ & $\begin{array}{l}\text { No. in } \\
\text { Fig. 1 }\end{array}$ \\
\hline $\mathrm{P}=\mathrm{N}$ & $1440-1170$ & $\mathrm{~S}$ & $(4)$ \\
$\mathrm{P}-\mathrm{O}-\mathrm{C}$ & $1050-970$ & $\mathrm{~S}$ & $(2)$ \\
& $830-740$ & & \\
$\mathrm{P}=\mathrm{O}$ & $1250-1150$ & $\mathrm{~S}$ & $(3)$ \\
$\mathrm{P}-\mathrm{O}-\mathrm{CH}_{2} \mathrm{CH}_{3}$ & $1850-1440$ & - & $(6)$ \\
$>\mathrm{N}-\mathrm{H}$ & 1640 & $\mathrm{~B}$ & $(7)$ \\
$\mathrm{CH}_{2}$ (hydrocarbon chain) & $\sim 720$ & $\mathrm{R}$ & $(1)$ \\
$\mathrm{CH}_{2}$ & 1465 & $\mathrm{~S}$ & $(5)$ \\
& $1350-1150$ & $\mathrm{~T}, \mathrm{~W}$ & \\
$\mathrm{CH}_{2}$ & 2853 (symmetry) & $\mathrm{S}$ & $(8)$ \\
& 2926 (asymmetry) & $\mathrm{S}$ & \\
End $\mathrm{CH}_{2}$ & 1416 & $\mathrm{~S} *$ & - \\
\hline
\end{tabular}

${ }^{a} \mathrm{~S}$ : stretch vibration; B: bending vibration; $\mathrm{R}$ : rocking vibration; $\mathrm{T}$ : twist vibration; $\mathrm{W}$ : wagging vibration; $\mathrm{S}^{*}$ : scissor vibration. them were decreased with the addition of MFR up to 20 phr, indicating that the crystallization rate increased with the addition of MFR. This was probably caused by the decrease of viscosity and the increase in the number of nucleation sites, when the MFR was added into LDPE. Yet, with more addition of MFR, it started to decrease. This is because the quantity amount of MFR started to aggregate due to the incompatibility between the MFR and LDPE. The aggregation of MFR hinders the crystallization of LDPE. After isothermal crystallization, samples were cooled down to $30^{\circ} \mathrm{C}$ and scanned again to $140^{\circ} \mathrm{C}$. The crystallinity was then calculated from the ratio of endothermic melting heat, $\Delta \mathrm{H}_{\mathrm{m}}$, to the $\Delta \mathrm{H}_{\mathrm{m}}{ }^{\circ}$, the melting heat of $100 \%$ perfect LDPE crystallites, $294 \mathrm{~J} / \mathrm{g}$. Table 4 shows the results of calculated crystallinity of LDPE in various blends after isothermal crystallization at $94^{\circ} \mathrm{C}$. It can be seen that the crystallinity increased with the addition of MFR. This is also the result of the decrease of viscosity and the increase of the heterogeneous nucleation with the addition of MFR oligomer.

\subsection{Thermal degradation behavior}

Fig. 6 shows the thermal gravimetric curves of various blends under nitrogen at a heating rate of $10^{\circ} \mathrm{C} / \mathrm{min}$. It can be seen that the thermal degradation of MFR occurred $120^{\circ} \mathrm{C}$ earlier than that of the neat LDPE. With the addition of MFR increasing in amount, the blend started to degrade earlier and earlier. Table 5 lists all the calculated values from the curves including the on-set degradation temperature $\left(T_{\text {on }}\right)$, maximum-rate

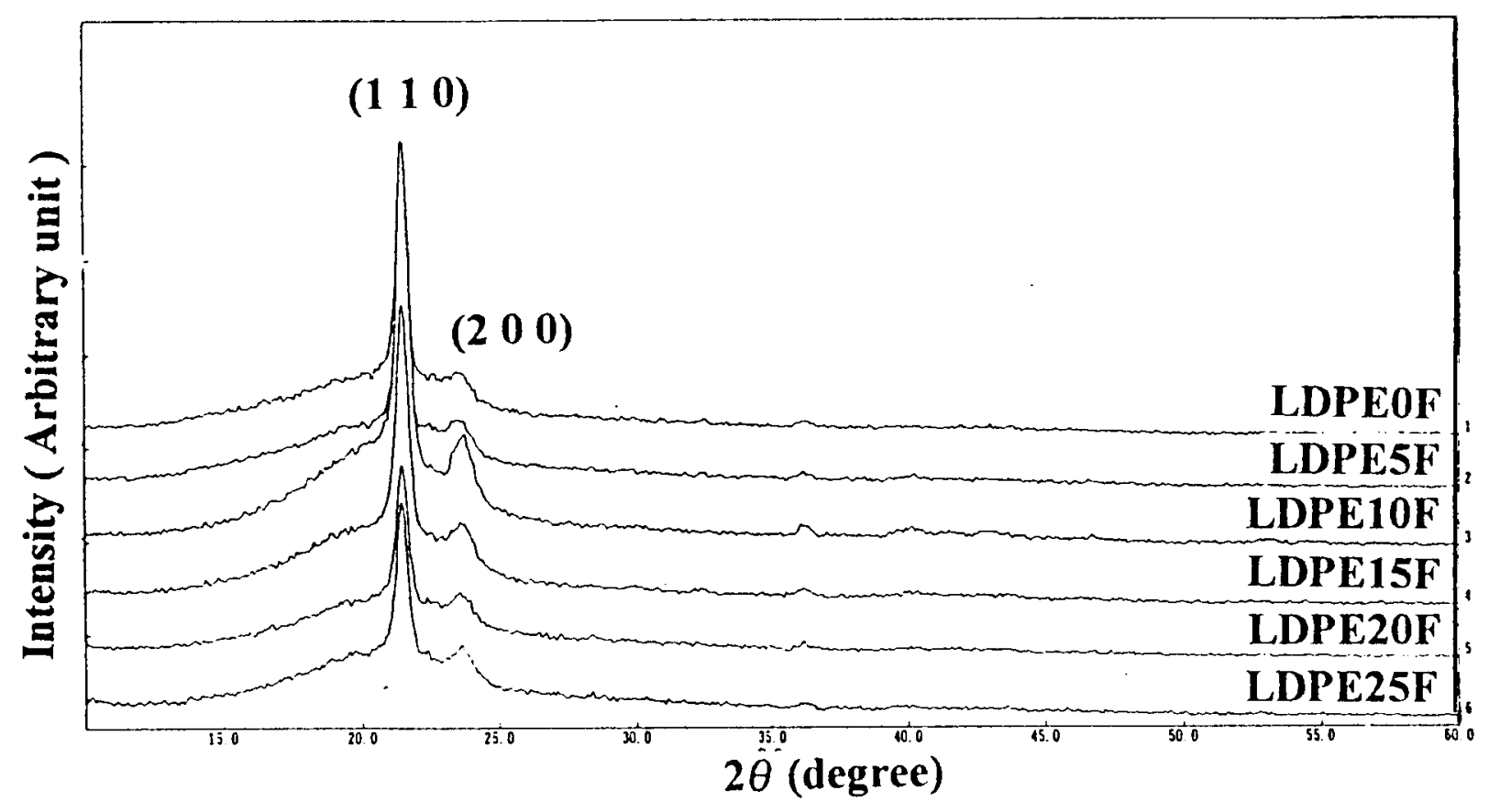

Fig. 2. The X-ray diffraction patterns of various LDPE blends. 


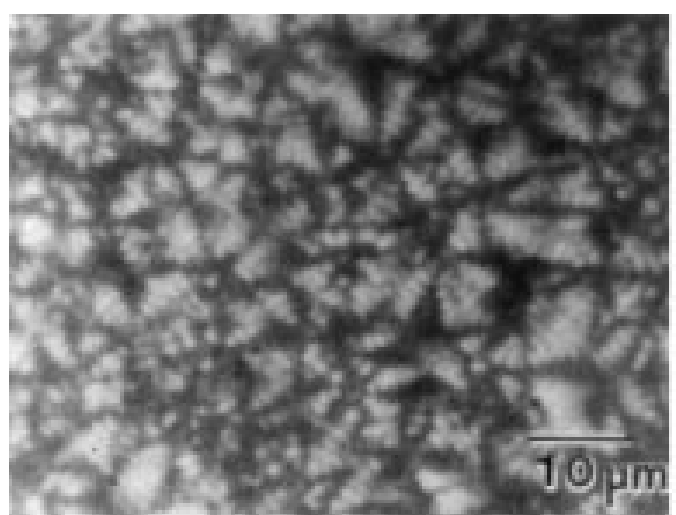

a. LDPE0F

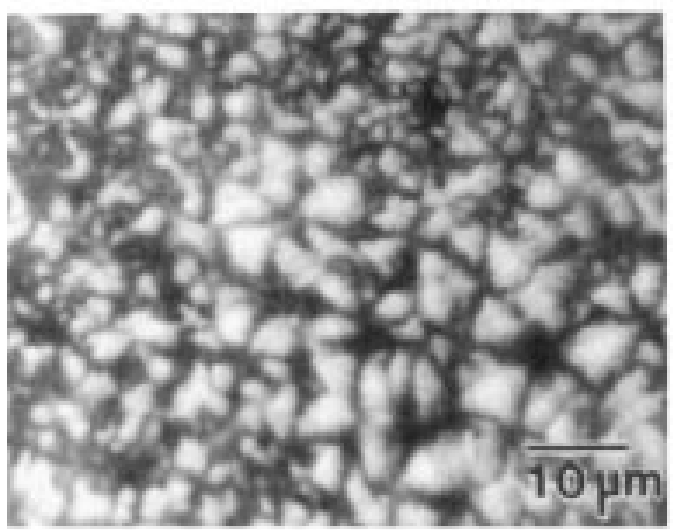

b. LDPE5F

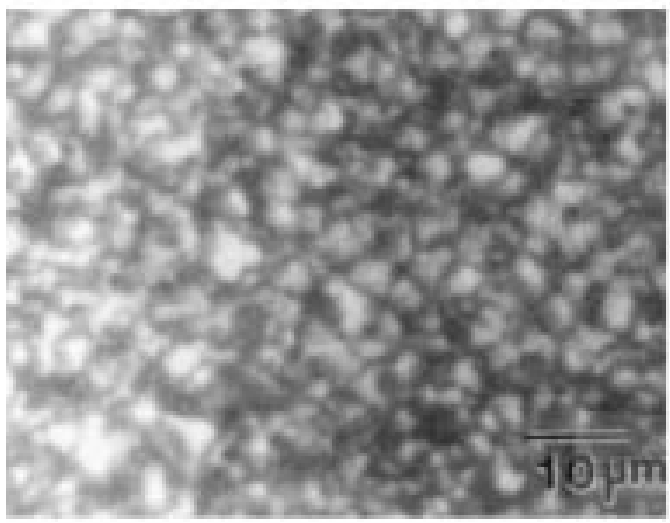

c. LDPE10F

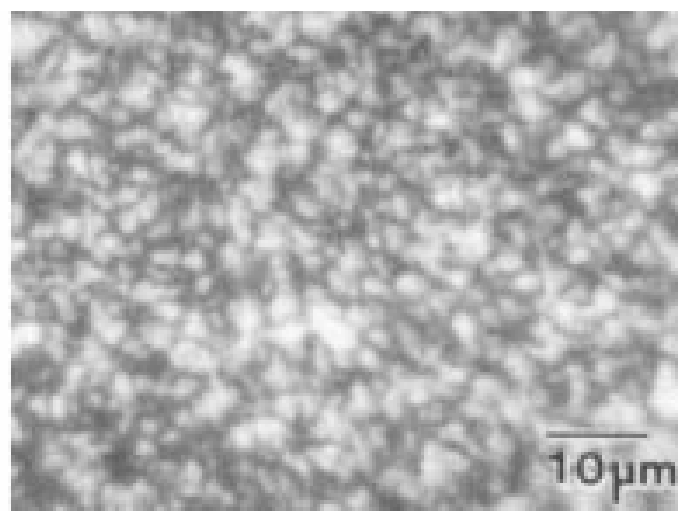

\section{d. LDPE15F}

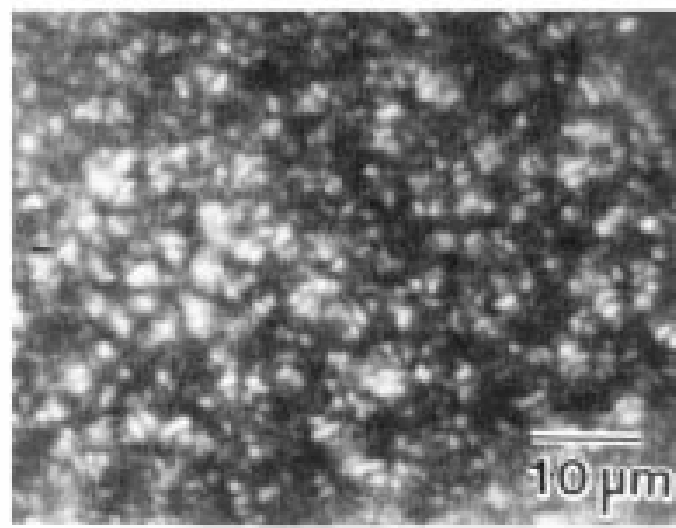

\section{e. LDPE20F}

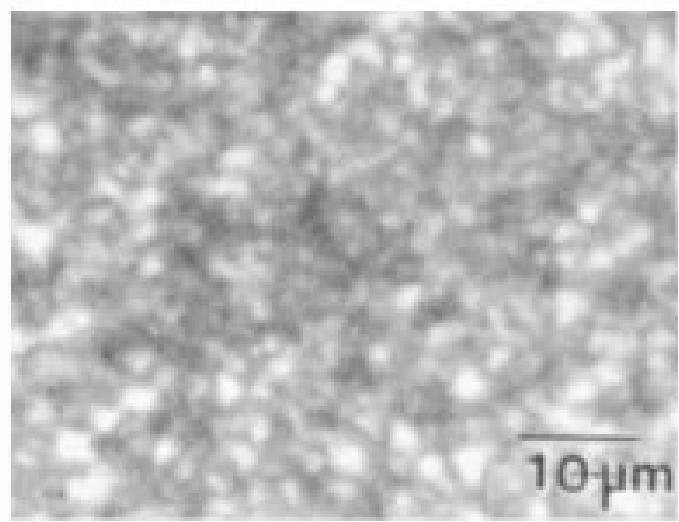

f. LDPE25F

Fig. 3. The optical micrographs of various LDPE blends after isothermal crystallization at $94^{\circ} \mathrm{C}$ for $3 \mathrm{~h}$.

degradation temperature $\left(T_{\max }\right)$ and the char yield at $650^{\circ} \mathrm{C}$. It can be seen from the table that the early degradation of the blend most probably caused by the degradation of MFR component did not accelerate the degradation of LDPE matrix. On the contrary, a slight increase in $T_{\max }$ was observed. In addition, the char yield at $650^{\circ} \mathrm{C}$ increased steadily with the addition of MFR. It has been pointed out that the degradation products of MFR component, such as phosphoric acid or poly(phosphoric acid), could form some thermally stable compounds on the condensed phase $[5,6]$. As a result, these compounds could protect the LDPE matrix from further degradation. In other words, MFR did have an effect in flame retardancy.

The relationship between weight loss fraction $(\alpha)$ and apparent activation energy $\left(E_{a}\right)$ can be calculated by 


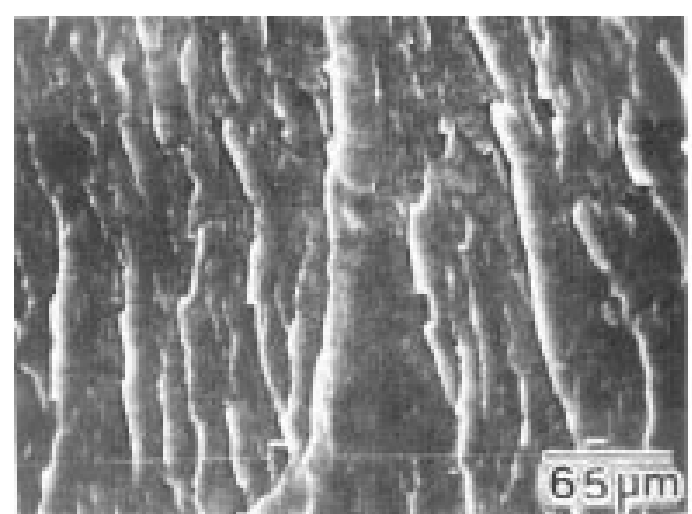

a. LDPE0F

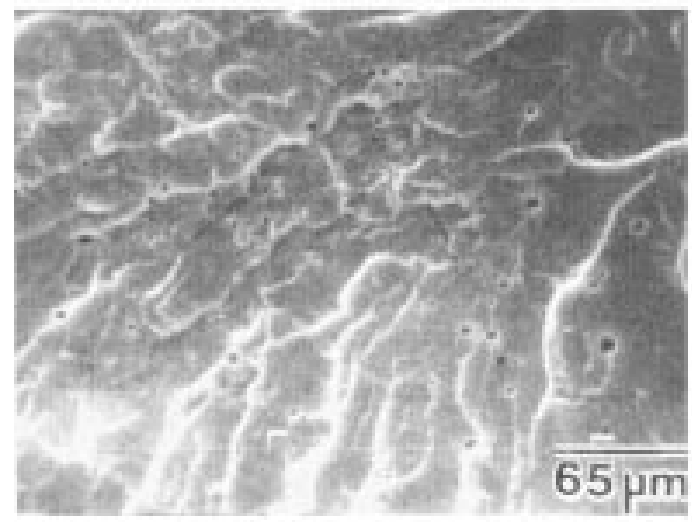

b. LDPE5F

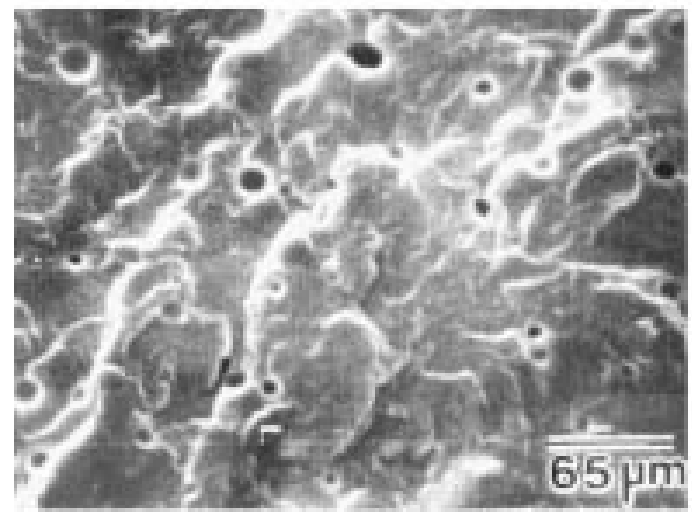

c. LDPE10F

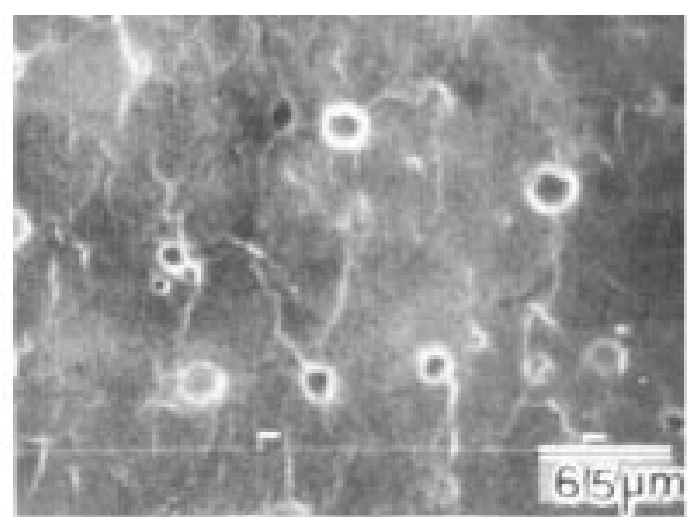

d. LDPE15F

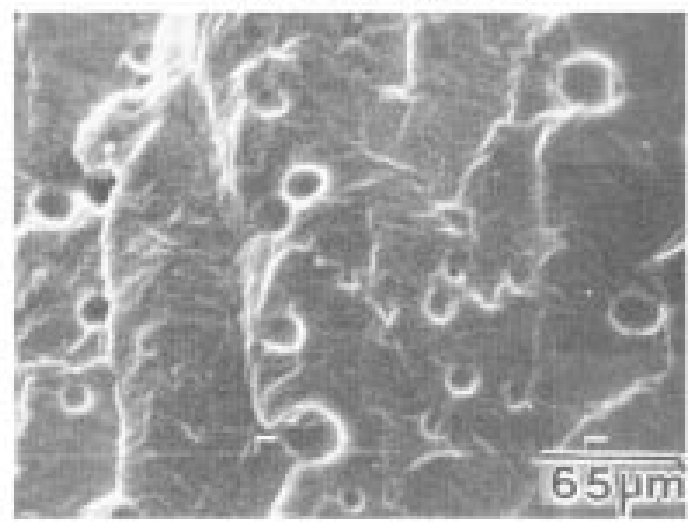

e. LDPE20F

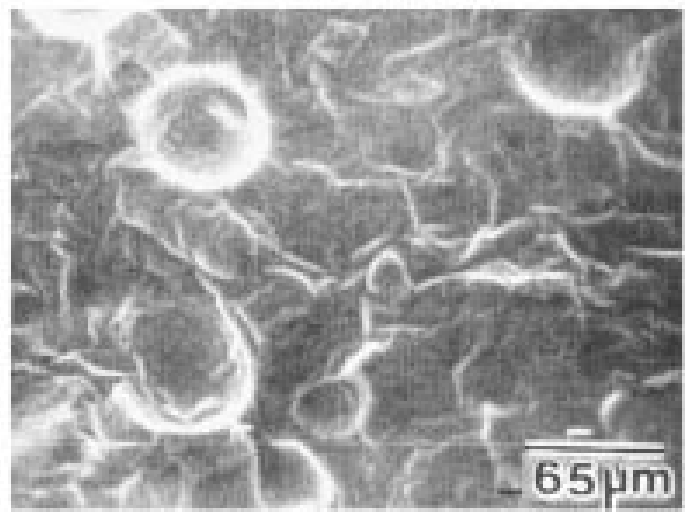

f. LDPE25F

Fig. 4. SEM micrographs of the fracture surface of various LDPE blends compared with a neat LDPE.

using Ozawa's method [7]. Fig. 7 shows several thermal degradation curves of LDPE10F at different heating rates (A); whereas Fig. 8 is their logarithm of heating rates $(\log A)$ versus reciprocal of temperature $(1 / T)$ at some certain conversions $(\alpha)$. The activation energies thus can be calculated from the slopes of these lines. Table 6 lists all the apparent activation energies at different conversions for various blends. As MFR was blended with LDPE, the activation energy at the initial stage of degradation ( $5 \%$ conversion) was decreased, after that, it was increased. These results support that the early degradation of MFR component would cause a decrease in $E_{a}$ at the beginning. Yet, it resulted in the formation of thermally stable compounds on the condensed phase, thus increasing the activation energy afterwards.

Fig. 9 shows the TGA curves of various blends at $10^{\circ} \mathrm{C} / \mathrm{min}$ heating rate under air atmosphere. Compared 
with the TGA curves in $\mathrm{N}_{2}$ (Fig. 6), the degradation temperature of LDPE main component and the char yield were both higher for the blends degraded in air. For example, the $T_{\max }$ and the char yield of LDPE20F were $490.4^{\circ} \mathrm{C}$ and $8.6 \%$, respectively, which were $24^{\circ} \mathrm{C}$ and $3.5 \%$ higher than the corresponding values in $\mathrm{N}_{2}$. All the calculated results are shown in the previous Table 5.

Table 3

The calculated parameters of various samples under isothermal crystallization $^{\mathrm{a}}$

\begin{tabular}{llllll}
\hline Sample & $T_{c}\left({ }^{\circ} \mathrm{C}\right)$ & $t_{\max }(\min )$ & $t_{1 / 2}(\min )$ & $n$ & $k$ \\
\hline LDPE0F & 97 & 6.2 & 6.5 & 2.65 & $4.99 \times 10^{-3}$ \\
& 96 & 5.2 & 5.4 & 2.66 & $7.70 \times 10^{-3}$ \\
& 95 & 4.1 & 4.3 & 2.67 & $1.42 \times 10^{-2}$ \\
& 94 & 3.2 & 3.3 & 2.68 & $2.92 \times 10^{-2}$ \\
& 93 & 2.3 & 2.4 & 2.70 & $6.64 \times 10^{-2}$ \\
LDPE10F & 97 & 5.9 & 6.3 & 2.53 & $6.70 \times 10^{-3}$ \\
& 96 & 5.1 & 5.4 & 2.54 & $9.90 \times 10^{-3}$ \\
& 95 & 4.2 & 4.4 & 2.55 & $1.60 \times 10^{-2}$ \\
& 94 & 3.1 & 3.3 & 2.55 & $3.39 \times 10^{-2}$ \\
& 93 & 2.2 & 2.3 & 2.57 & $7.96 \times 10^{-2}$ \\
LDPE20F & 97 & 4.7 & 5.0 & 2.44 & $1.37 \times 10^{-2}$ \\
& 96 & 3.6 & 3.8 & 2.42 & $2.56 \times 10^{-2}$ \\
& 95 & 2.8 & 2.9 & 2.47 & $4.91 \times 10^{-2}$ \\
& 94 & 2.1 & 2.2 & 2.48 & $9.71 \times 10^{-2}$ \\
& 93 & 1.7 & 1.8 & 2.50 & $1.67 \times 10^{-1}$ \\
LDPE25F & 97 & 5.1 & 5.7 & 2.21 & $1.48 \times 10^{-2}$ \\
& 96 & 4.0 & 4.5 & 2.23 & $2.48 \times 10^{-2}$ \\
& 95 & 3.3 & 3.6 & 2.24 & $3.90 \times 10^{-2}$ \\
& 94 & 2.8 & 3.0 & 2.24 & $5.73 \times 10^{-2}$ \\
& 93 & 2.1 & 2.3 & 2.26 & $1.10 \times 10^{-1}$ \\
\hline
\end{tabular}

${ }^{a} T_{c}$, crystallization temperature; $t_{\max }$ : the time needed to reach the maximum of the exothermic peak; $t_{1 / 2}$ : the time needed to reach $50 \%$ relative crystallinity (half-life time); $n$ and $k$ are the exponent and rate constant in Avrami equation.

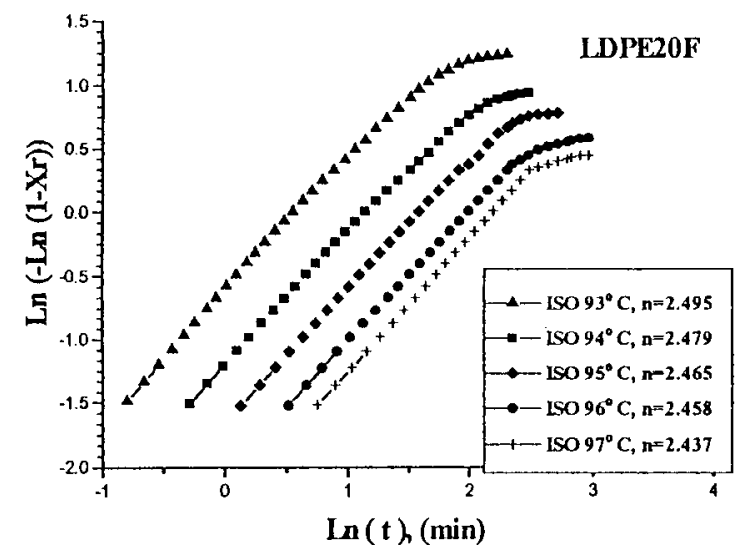

Fig. 5. Several plots of $\ln \left(-\ln \left(1-X_{r}\right)\right)$ versus $\ln (t)$ in order to determine the Avrami parameters, $n$ and $k$.

\subsection{Flammability}

The last column in Table 7 shows limiting oxygen index (LOI) values of various blends following ASTM D2863 method. It can be seen that the LOI value increased from 21.0 for a neat LDPE to 23.6 for a LDPE blended with 20 phr MFR. Thus, the addition of

Table 4

The calculated crystallinity of various samples under isothermal crystallization at $94^{\circ} \mathrm{C}$

\begin{tabular}{llll}
\hline Sample & $\Delta H_{m}(\mathrm{~J} / \mathrm{g})$ & $\Delta H_{m}(\mathrm{~J} / \mathrm{g}$ LDPE $)$ & Crystallinity $(\%)$ \\
\hline LDPE0F & 32.4 & 32.4 & 11.1 \\
LDPE5F & 49.7 & 52.2 & 17.8 \\
LDPE10F & 43.8 & 48.1 & 16.4 \\
LDPE15F & 41.8 & 50.1 & 17.1 \\
LDPE20F & 47.4 & 54.5 & 18.6 \\
LDPE25F & 39.7 & 49.6 & 16.9 \\
\hline
\end{tabular}

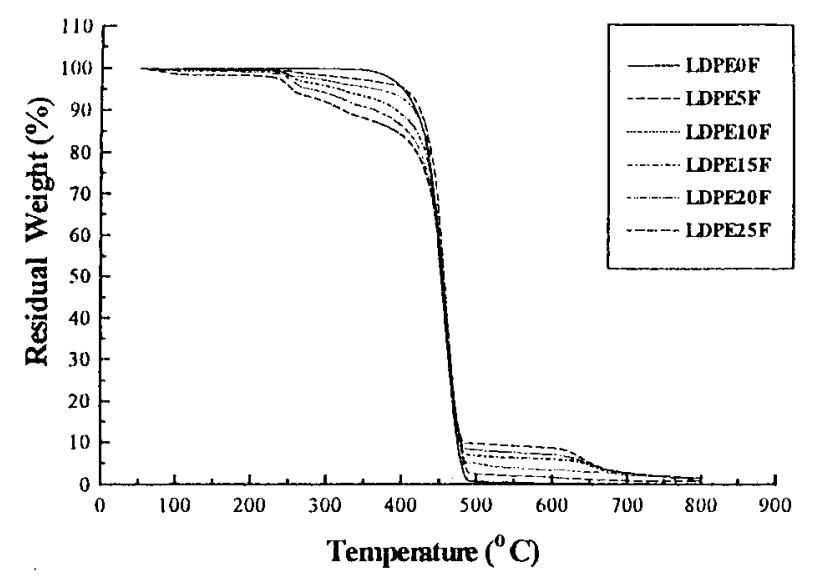

Fig. 6. The TGA curves of various LDPE blends at a heating rate of $10^{\circ} \mathrm{C} /$ min under $\mathrm{N}_{2}$.

Table 5

The calculated results from Tga curves of various samples (heating rate was $10^{\circ} \mathrm{C} / \mathrm{min}$ )

\begin{tabular}{|c|c|c|c|c|c|c|}
\hline \multirow[t]{2}{*}{ Sample } & \multicolumn{3}{|c|}{ In $\mathrm{N}_{2}$ atmosphere } & \multicolumn{3}{|c|}{ In air atmosphere } \\
\hline & $\begin{array}{l}\mathrm{T}_{\text {on }}{ }^{\mathrm{a}} \\
\left({ }^{\circ} \mathrm{C}\right)\end{array}$ & $\begin{array}{l}\mathrm{T}_{\max } \mathrm{b} \\
\left({ }^{\circ} \mathrm{C}\right)\end{array}$ & $\begin{array}{l}Y_{c}{ }^{c} \\
(\%)\end{array}$ & $\begin{array}{l}\mathrm{T}_{\text {on }}{ }^{\mathrm{a}} \\
\left({ }^{\circ} \mathrm{C}\right)\end{array}$ & $\begin{array}{l}\mathrm{T}_{\max } \mathrm{b} \\
\left({ }^{\circ} \mathrm{C}\right)\end{array}$ & $\begin{array}{l}Y_{c}^{c} \\
(\%)\end{array}$ \\
\hline MFR & 288.7 & 299.9 & 38.1 & 265.3 & 315.3 & 42.3 \\
\hline LDPE0F & 409.0 & 452.5 & 0.9 & 365.9 & 460.7 & 3.5 \\
\hline LDPE5F & 407.1 & 462.3 & 1.5 & - & - & - \\
\hline LDPE10F & 370.8 & 464.8 & 2.0 & 358.3 & 471.8 & 7.8 \\
\hline LDPE15F & 325.8 & 465.3 & 3.7 & - & - & - \\
\hline LDPE20F & 295.0 & 466.0 & 5.1 & 315.9 & 490.4 & 8.6 \\
\hline LDPE25F & 260.3 & 466.3 & 8.6 & 290.5 & 499.7 & 8.7 \\
\hline
\end{tabular}

a $T_{\text {on }}$ was the on-set degredation temperature (temperature at $5 \%$ weight loss).

b $T_{\max }$ was the maximum-rate degredation temperature.

c $Y_{\mathrm{c}}$ was the char yield at $650^{\circ} \mathrm{C}$. 
MFR improved the flame retardancy of LDPE. Table 7 also lists all the calculated values from the smoke density measurement, including $t_{\mathrm{D} 16}, D_{m}, R$ and SOI. It shows that $t_{\mathrm{D} 16}$ was decreased as the amount of MFR additive increased, indicating that the addition of MFR

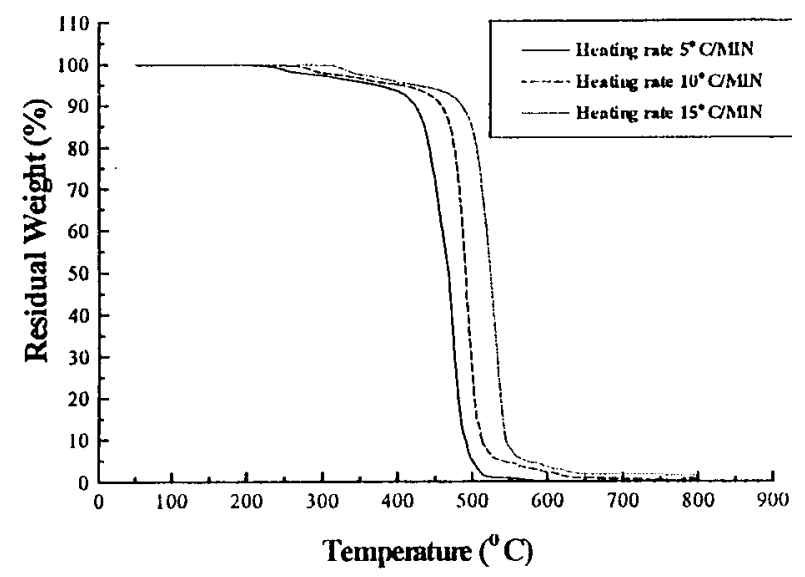

Fig. 7. The thermal degradation curves of a LDPE10F blend at different heating rates.

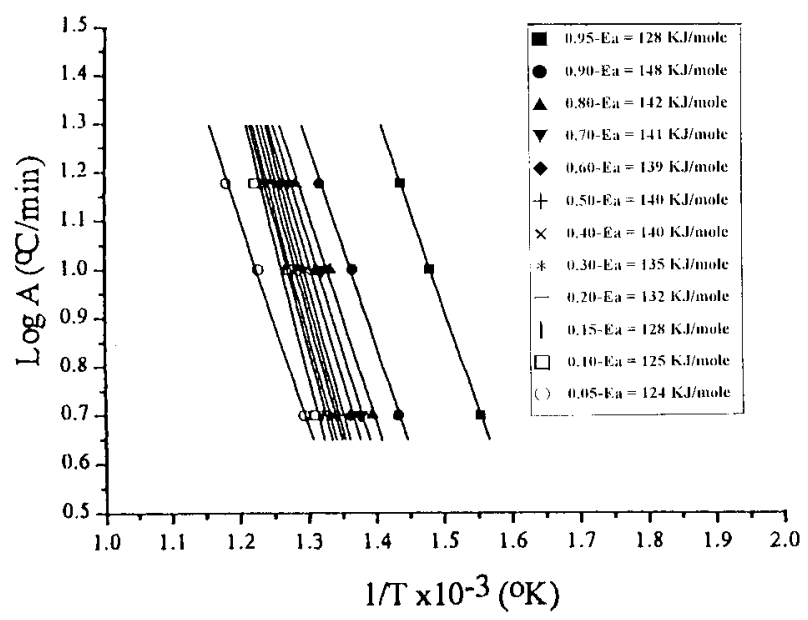

Fig. 8. Several plots of logarithm of heating rate $(A)$ versus reciprocal temperature $(1 / T)$ at different conversions for a LDPE10F blend.

Table 6

The apparant activation energies of various samples under thermal degredation in $\mathrm{N}_{2}$

\begin{tabular}{lrrrrrrrrrrrr}
\hline Sample & \multicolumn{1}{l}{ Activation energy $E_{a}(\mathrm{~kJ} / \mathrm{mol})$} \\
\cline { 2 - 10 } & \multicolumn{2}{l}{ Conversion, $\alpha^{\mathrm{a}}$} \\
& 0.05 & 0.10 & 0.20 & 0.30 & 0.40 & 0.50 & 0.60 & 0.70 & 0.80 & 0.90 \\
\hline MFR & 90.9 & 110.7 & 125.8 & 143.9 & 153.0 & 68.5 & 85.2 & 100.7 & 108.9 & - \\
LDPE0F & 141.7 & 142.4 & 135.2 & 136.1 & 137.8 & 135.7 & 135.6 & 134.0 & 133.6 & 128.9 \\
LDPE10F & 128.3 & 148.3 & 142.0 & 140.8 & 139.9 & 139.9 & 140.4 & 135.5 & 132.4 & 125.3 \\
LDPE20F & 112.4 & 176.8 & 145.9 & 142.9 & 146.4 & 147.5 & 147.4 & 148.6 & 149.3 & 116.8 \\
LDPE25F & 73.7 & 92.8 & 193.8 & 163.6 & 154.7 & 148.6 & 146.3 & 141.2 & 120.1 & - \\
\hline
\end{tabular}

a $\alpha=[100-$ residual wt (\%) in TGA]/100. did not improve the reduction of smoke density at the initial stage. This is because MFR degraded earlier than LDPE. Yet, the maximum optical density $D_{m}$ and the rate of increase in smoke density $R$ were decreased with the addition of MFR, especially for LDPE5F. Therefore, the early degradation of MFR, though causing an early production of smoke, had reduced the overall smoke density and the rate of increase in smoke density. This is beneficial in flame retardancy.

\subsection{Tensile mechanical properties}

The tensile mechanical properties of the various blends were measured at a speed of $20 \mathrm{~mm} / \mathrm{min}$. The modulus, ultimate tensile strength and the elongation at break were all decreased with the addition of MFR up to $20 \mathrm{phr}$ (Fig. 10). This is because the soft inclusion of MFR dispersed in the LDPE matrix without any strong bonding between the particles and matrix. Therefore, these MFR particles, like voids, acted as stress concentrators, which deteriorated the mechanical properties of LDPE.

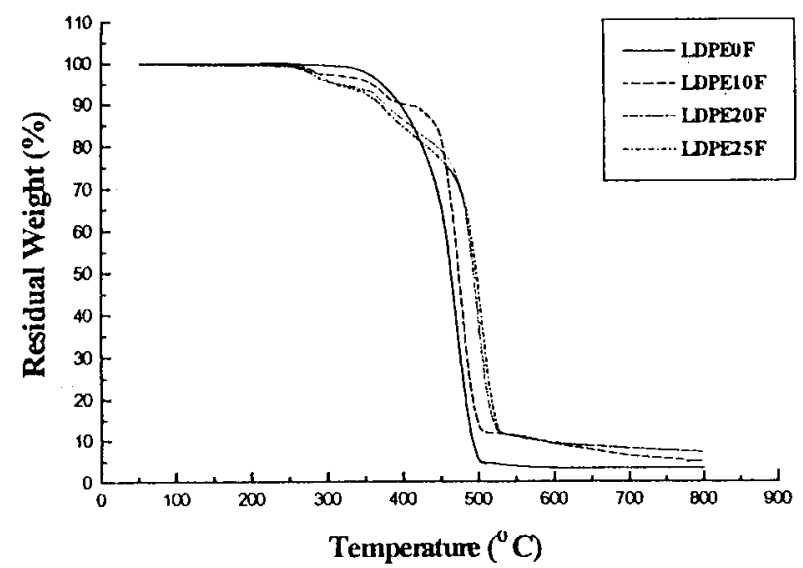

Fig. 9. The TGA curves of various LDPE blends at a heating rate of $10^{\circ} \mathrm{C} / \mathrm{min}$ under air.

Table 7

The limiting oxygen index and various parameters calculated from smoke density measurement ${ }^{\mathrm{a}}$

\begin{tabular}{llrrrr}
\hline Sample & $t_{\mathrm{D} 16}(\mathrm{~s})$ & \multicolumn{1}{c}{$D_{m}$} & \multicolumn{1}{c}{$R$} & SOI & LOI \\
\hline LDPE0F & 304 & 141 & 19.0 & 5.3 & 21.0 \\
LDPE5F & 208 & 77 & 6.8 & 1.5 & 21.4 \\
LDPE10F & 182 & 105 & 11.3 & 3.9 & 22.8 \\
LDPE15F & 141 & 107 & 12.5 & 5.7 & 23.0 \\
LDPE20F & 126 & 123 & 16.9 & 9.9 & 23.6
\end{tabular}

a $t_{\mathrm{D} 16}$, the time required to reach specific optical density $=16 ; D_{m}$ : the maximum smoke density; $R$ : the rate of increase in smoke density; SOI: index of the reduction in visibility or smoke obscuration index; LOI: limiting oxygen index. 

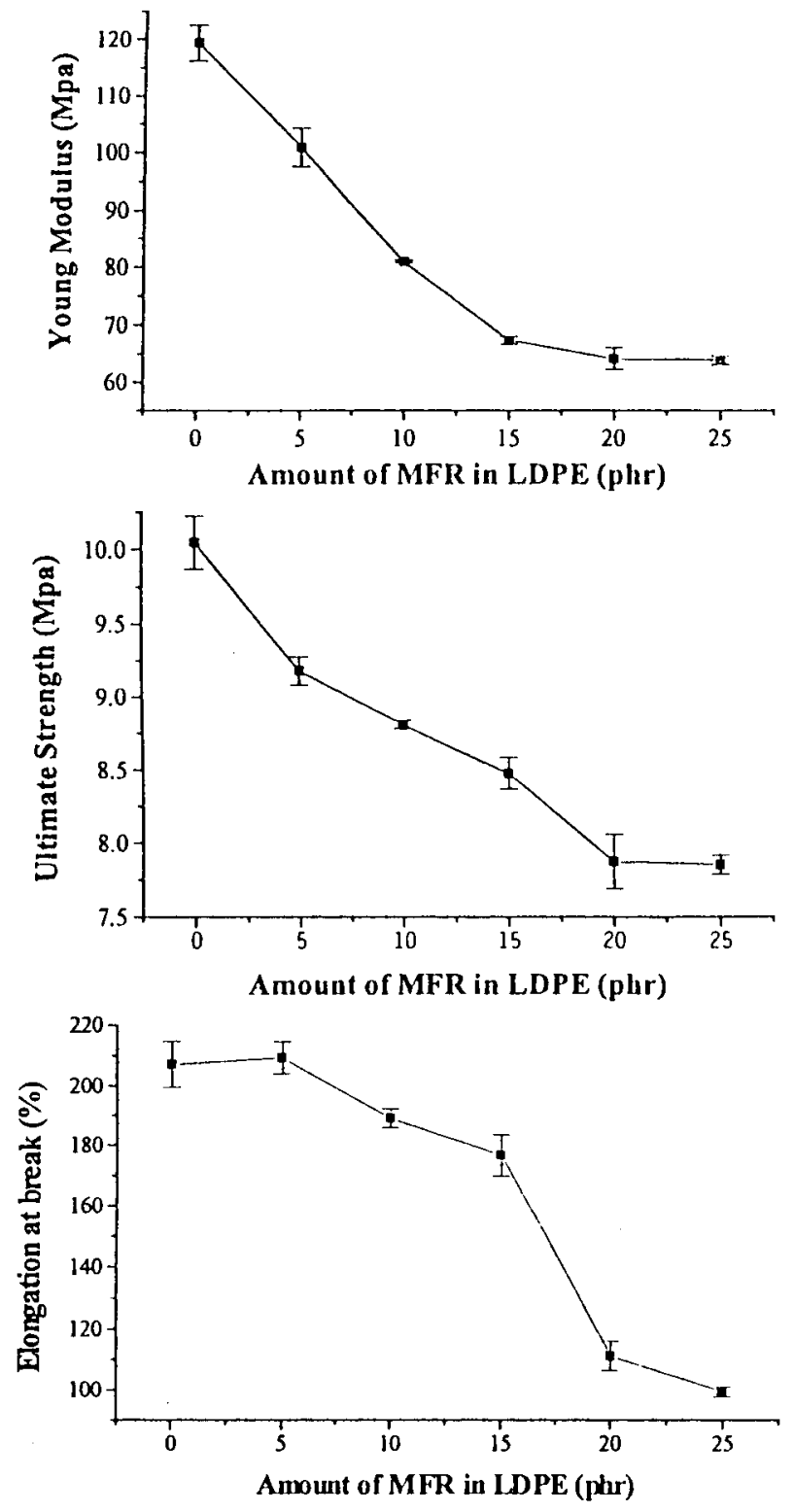

Fig. 10. The tensile mechanical properties of various LDPE blends with different amount of MFR.

\section{Conclusions}

1. LDPE was melt blended with different amount of MFR flame retardant in a Brabender. It was found that MFR phase separated from LDPE matrix with very weak interfacial bonding.

2. The X-ray diffraction patterns revealed two peaks corresponding to the (110) and (200) reflections from the orthorhombic polyethylene crystals for all the blends up to $25 \mathrm{phr}$ MFR. In addition, polarized optical microscope shows spherulitic structures for all the blends, yet, the size of spherulites decreased with the addition of MFR.

3. The crystallization rate and the crystallinity of LDPE were increased with the addition of MFR under isothermal crystallization at various temperatures from 93 to $97^{\circ} \mathrm{C}$. This was attributed to the decrease in viscosity and increase in the number of nucleation sites due to the addition of MFR oligomer.

4. With the addition of MFR in LDPE, the maximum-rate degradation temperature, char yield at $650^{\circ} \mathrm{C}$ and the limiting oxygen index values were all increased. These results indicated that the addition of MFR was advantageous in flame retardancy.

5. Because of the soft inclusion of MFR and weak interfacial bonding, the MFR additive deteriorated the tensile mechanical properties of LDPE.

\section{Acknowledgements}

The authors would like to thank Chung Shan Institute of Science and Technology (CSIST), Taiwan, ROC for their financial support.

\section{References}

[1] Straus SSL, Madorsky D, William L. J Polym Sci 1949;4:639.

[2] Tsuchiya Y, Sumi K. J Polym Sci, Part A-1 1968;6:415.

[3] Grassie N. In: Mark HF, editor. Encyclopedia of polymer science and technology, vol 14, 2nd ed. New York: Wiley, 1985. p. 65 .

[4] Seeger M, Barrull EM. J Polym Sci, Polym Chem 1975;13:1515.

[5] Grassie N, Scott G. Polymer degradation and stability. Cambridge: Cambridge University Press, 1985 [Chapter 6].

[6] Wang P-S, Denq B-L, Chiu W-Y, Don T-M, Chiu Y-S. Polym Degrad Stab, in press.

[7] Ozawa T. Bull Chem Soc Jpn 1965;38:1881. 